\title{
Analisis Produktivitas Tukang terhadap Beban Kerja pada Pekerjaan Jalan
}

\author{
${ }^{1}$ Kiki Rizky Amalia, ${ }^{2}$ Seprisal \\ ${ }^{1}$ Dosen Fakultas Teknik Sipil Universitas Batanghari Jambi \\ ${ }^{2}$ Mahasiswa Teknik Sipil Universitas Batanghari Jambi \\ Email : iqy.amalia@gmail.com
}

\begin{abstract}
Human resources (labor) are the most difficult factors predicted by productivity because they have very many variables, both internal (age, ethnicity, experience, motivation, education) and external ones (composition of work groups, environment, supervision, system payroll). Labor is an expensive resource, and is a factor of production that contributes greatly to the completion of the project, because it is the workforce that manages and controls the material and work equipment. In this study the survey began from September 2017 to December 2017. The survey was conducted on the Sei. Saren-Teluk Nilau-Senyerang-Batas Riau road project. To complete the survey survey data carried out on 12 people who were scattered and 12 people pembesian, in which the masons are accustomed to doing their work with work experience that has been obtained, which each observation is done three working days, with three times a day for 30 minutes in one day. In artisan research, the productivity volume produced by artisans varies considerably between the first, second and third days, but the difference in productivity is not much different. This can be seen from the results of research which show that the average productivity produced on the first day is $0.64 \mathrm{M} 2$ / minute, while on the second day the resulting productivity is $0.59 \mathrm{M} 2$ / minute and on the third day is 0.85 M2 / minute. This data shows that the productivity produced every day is not much different. In this observation, it can also be seen the artisan productivity figures produced for three days with a variety of data collection in the morning, afternoon and evening, where the average value of productivity for three days is $0.69 \mathrm{M} 2$ / minute and $16.5 \mathrm{M} 2$ / artisan .
\end{abstract}

Keywords: Productivity Analysis, artisan variation on productivity.

\section{PENDAHULUAN}

Sumber daya manusia (tenaga kerja) merupakan faktor yang paling sulit di prediksi produktivitasnya karena memiliki variabel yang sangat banyak, baik bersifat intern (umur, etnis, pengalaman, motivasi, pendidikan) maupun yang bersifat ekstern (komposisi kelompok kerja, lingkungan, pengawasan, sistem penggajian). Tenaga kerja merupakan sumber daya yang mahal, dan merupakan faktor produksi yang memberikan andil besar pada penyelesaian proyek, karena tenaga kerjalah yang mengatur dan mengontrol material serta peralatan kerja.

Di negara yang sedang berkembang seperti Indonesia, sangat dibutuhkan terselenggaranya pembangunan yang dilandasi dengan prinsip efisiensi dan efektivitas. Hal tersebut diperlukan untuk mengatasi keterbatasan sumber daya yang ada, sehingga tercipta produktivitas yang tinggi. Produktivitas menjadi isu dominan dalam industri jasa konstruksi. Dengan produktivitas yang tinggi, akan dicapai efisiensi pemakaian sumber daya serta penghematan biaya, sehingga perusahaan konstruksi akan meraih hasil yang memadai serta memiliki daya saing yang tinggi.

Jam kerja normal yang umumnya diterapkan adalah 8 jam, yaitu mulai pukul 08.00 hingga pukul 16.00, dengan istirahat satu jam pada pukul 12.00 hingga pukul 13.00. Namun demikian, waktu yang sesungguhnya dihabiskan oleh pekerja untuk bekerja tidaklah penuh 7 jam.

Dalam proyek konstuksi dapat di pengaruhi oleh produktivitas, yang mana produktivitas dapat di ukur secara kasar presentase biaya yang di dapat suatu proyek kontruksi itu sendiri, beberapa faktor yang mempengaruhi produktivitas pada pekerja konstruksi adalah :Manajemen, Teknologi (material, peralatan, dan metoda), Peraturan-peraturan,Tenaga kerja.

Dalam proyek kontruksi tukang atau pekerja tidak akan dapat melakukan pekerjaannya sesuai dengan waktu kerja yang di tentukan, di karenakan beberapa kendala yang akan terjadi pada pekerja tersebut.

Adapun faktor-faktor yang mempengaruhi produktivitas tenaga kerja adalah :

1. Kapabilitas sumber daya : perilaku, budaya, kebiasaan, etika kerja.

2. Kelelahan fisik

Menurut Wulfram (2002), Produktivitas tenaga kerja dapat dikategorikan menjadi tiga peringkat, yaitu bekerja efektif, mempersiapkan pekerjaan utama dan menganggur.

1. Bekerja efektif adalah segala aktivitas yang secara langsung merupakan proses nyata dari penambahan unit hasil pekerjaan.

2. Mempersiapkan pekerjaan utama tidak secara langsung memberikan tambahan hasil pekerjaan, namun diperlukan untuk melaksanakan suatu pekerjaan, seperti : mempelajari gambar konstruksi, memasang scaffolding, mengukur, mempersiapkan material dan tempat kerja.

3. Menganggur adalah aktivitas yang tidak memberikan tambahan hasil apapun, seperti : berjalan tanpa tujuan, merokok, menunggu material, memperbaiki kesalahan pekerjaan.

Secara umum produktivitas diartikan sebagai suatu perbandingan antara hasil keluaran dan masukan. Masukan dibatasi dengan masukan tenaga kerja, sedangkan keluaran diukur dalam kesatuan fisik bentuk dan nilai. Produktivitas juga diartikan sebagai tingkatan efisiensi dalam memproduksi barang dan jasa. 
Produktivitas adalah suatu pendekatan untuk menentukan tujuan yang efektif, pembuatan rencana, aplikasi penggunaan cara yang produktif untuk menggunakan sumber-sumber yang efisien dan tetap menjaga kualitas tetap tinggi.

Peraturan tentang ketenagakerjaan telah diatur secara khusus dalam Undang-Undang No.13 Tahun 2003 Pasal 77 sampai Pasal 85, dimana,pasal 77 ayat 1, Undang-Undang No.13/2003. Mewajibkan setiap pengusaha untuk melaksanakan ketentuan-ketentuan jam kerja ini mengataur 2 sistem yaitu:

1. 7 jam kerja dalam 1 hari atau 40 jam kerja dalam 1 minggu untuk 6 hari kerja dalam 1 minggu.

2. 8 jam kerja dalam 1 hari atau 40 jam kerja dalam 1 minggu untuk 5 hari kerja dalam 1 minggu.

Pada kedua system jam kerja tersebut juga diberikan batasan jam kerja yaitu 40 (empat puluh) jam dalam 1 ( satu ) mingggu, apabilah melebihi dari ketentuan waktu kerja tersebut, maka waktu kerja kerja biasa dianggap masuk sebagai waktu lembur, sehingga pekerja berhak atas upah lembur.

Jumlah jam kerja yang efisien untuk seminggu adalah antara 40 - 48 jam yang terbagi dalam 5 atau 6 hari kerja. Maksimum waktu kerja tambahan yang masih efisien adalah 30 menit. Sedangkan di antara waktu kerja harus disediakan waku isitrahat yang jumlahnya antara $15-30 \%$ dari seluruh waktu kerja.

Apabila jam kerja melebihi dari ketentuan tersebut akan ditemukan hal-hal seperti: penurunan kecepatan kerja, gangguan kesehatan, angka absensi karena sakit meningkat, yang semuanya akan bermuara kepada rendahnya tingkat produktivitas kerja.

Istirahat diperlukan untuk memulihkan kesegaran fisik ataupun mental tenaga kerja. Jumlah total waktu yang diperlukan untuk istirahat rata - rata $15 \%$ dari total waktu kerja, untuk kerja fisik biasa. Untuk pekerjaan normal fisik berat (kerja berat/kasar), prosentase waktu istirahat yang diperlukan bisa mencapai 30\%. Beberapa penelitian membuktikan bahwa pengaturan jadwal kerja yang diselingi dengan beberapa kali waktu istirahat akan menaikkan efisiensi pada pekerja itu sendiri.

\section{METODE PENELITIAN}

Penelitian ini dilakukan di Kecamatan Bram Itam Kabupaten Tanjung Jabung Barat Provinsi Jambi.

Adapun penelitian ini disusun dengan tahapan sebagai berikut :

1. Mengumpulkan beberapa literature.

2. Mengumpulkan data sekunder berupa data- data yang dari para peneliti yang terdahulu, yang berkaitan dengan penyusunan tugas akhir ini.

3. Mengumpulkan data primer yang berupa, data jumlah tukang yang bekerja di lapangan, Data Waktu istirahat Tukang di lapangan, Data hasil pekerjaan selama 30 menit.

4. Tinjauan lapangan kegiatan yang terjun langsung melakukan pengamatan pekerjaan di lapangan.

5. Melakukan pengamatan terhadap objek yang akan teliti yaitu berupa pekerja tukang hampar dan pembesian.

6. Menganalisa data-data yang didapat dilapangan baik secara langsung maupun dari pihak kontraktor.

7. Membuat kesimpulan dan saran berupa hasil produktivitas rata-rata yang dihasilkan para pekerja atau tukang.

\section{HASIL DAN PEMBAHASAN}

Adapun data-data yang diperlukan dalam penelitian ini yaitu. Data primer untuk penelitian ini berupa data jumlah tukang yang bekerja dilapangan yang berjumlah 24 orang, data waktu isrirahat tukang, data jumlah kubikasi beton yang terhampar, data jumlah pemasangan hamparan besi.

Dalam penyelesaian penelitian ini survey dimulai dari September 2017 sampai dengan Desember 2017. Adapun survey dilakukan pada proyek pekerjaan jalan Sei.Saren- Teluk Nilau-Senyerang-Batas Riau Desa Bram Hitam Kabupaten Tanjung Jabung Barat. Untuk melengkapi data survey pengamatan dilakukan terhadap 12 orang tukang hampar dan 12 orang tukang pembesian, yang mana para tukang ini suda terbiasa melakukan pekerjaannya dengan pengalaman kerja yang telah didapat, yang mana setiap pengamatan dilakukan tiga hari kerja, dengan tiga kali sehari selama 30 menit dalam satu hari.

Tabel 1. Profil Tukang Berdasarkan Jenjang Pendidikan

\begin{tabular}{cccc}
\hline No & Pendidikan Terakhir & Jumlah & Presentase \\
\hline 1 & SD & 2 & $8,33 \%$ \\
2 & SLTP & 6 & $25 \%$ \\
3 & SLTA & 16 & $66,67 \%$ \\
& Jumlah & $\mathbf{2 4}$ & $\mathbf{1 0 0} \%$ \\
\hline
\end{tabular}

Sumber : Data Olahan 2018

Dari tabel diatas menunjukan rekapitulasi tukang berdasarkaan jenjang pendidikan, maka diketahui mayoritas pendidikan tukang yang berkerja adalah tamatan SLTA dengan persentasi $66,67 \%$, untuk tamatan SLTP dengan persentasi $25 \%$, dan $8,33 \%$ tamatan SD. 
Tabel 2. Profil Tukang Berdasarkan Pengalaman Kerja

\begin{tabular}{|c|c|c|c|}
\hline No & Pengalaman kerja (th) & Jumlah (Orang) & Presentase \\
\hline 1 & $2 \mathrm{~s} / \mathrm{d} 4$ & 19 & $79,17 \%$ \\
\hline 2 & $5 \mathrm{~s} / \mathrm{d} 8$ & $\begin{array}{c}5 \\
24\end{array}$ & $20,83 \%$ \\
\hline
\end{tabular}

Sumber : Data Olahan 2018

Berdasarkan hasil pengamatan dan data pada Tabel 2 merupakan rekapitulasi profil tukang berdasarkan pengalaman kerja yang mana dari hasil

tersebut didapat pengalaman tukang 2 tahun sampai dengan 4 tahun dengan jumlah $79,17 \%$ dan pengalaman tukang 5 sampai dengan 8 tahun berjumlah 20,83\%.

Tabel 3. Pengamatan Tukang Hampar

\begin{tabular}{|c|c|c|c|c|c|}
\hline \multicolumn{6}{|c|}{ TABEL PENGAMATAN } \\
\hline No & $\begin{array}{l}\text { Hari \& } \\
\text { Tanggal }\end{array}$ & $\begin{array}{c}\text { Jam } \\
\text { Pengamatan }\end{array}$ & $\mathrm{M}^{3}$ beton & $\begin{array}{c}\text { Produktivitas } \\
\mathrm{M}^{2}\end{array}$ & Cacatan \\
\hline \multirow{4}{*}{1} & \multirow{3}{*}{$10 / 10 / 2017$} & 09:00- 09:30 & 12 & 19,2 & Dikerjakan oleh 12 orang Tukang \\
\hline & & $11: 00-11: 30$ & 9 & 14,4 & Hampar dengan ukuran $2,5 \mathrm{M} \times 0,25$ \\
\hline & & $14: 00-14: 30$ & 15 & 24 & $\mathrm{M}$ \\
\hline & & 08:30- 09:00 & 12 & 19,2 & Dikerjakan oleh 12 orang Tukang \\
\hline \multirow{3}{*}{2} & \multirow{3}{*}{$11 / 10 / 2017$} & $10: 15-10: 45$ & 6 & 9,6 & Hampar dengan ukuran 2,5 M x 0,25 \\
\hline & & $14: 30-15: 00$ & 15 & 24 & M \\
\hline & & $09: 20-09: 50$ & 18 & 28,8 & \\
\hline \multirow[t]{3}{*}{3} & \multirow[t]{2}{*}{$12 / 10 / 2017$} & $11: 15-11: 45$ & 12 & 19,2 & Dikerjakan oleh 12 orang lukang \\
\hline & & $15: 00-15: 30$ & 18 & 28,8 & $\begin{array}{l}\text { Hampar dengan ukuran } 2,5 \text { IVI X } 0,25 \\
\qquad M\end{array}$ \\
\hline & Jumlah & 270 menit & 117 & 187,2 & \\
\hline
\end{tabular}

Sumber : Data olahan 2018

Hasil pengamatan adalah berupa siklus waktu pelaksanaan penghamparan beserta produktivitas yang dihasilkan selama 30 menit, apabilah dilihat dari tabel diatas semakin sore maka produktivitas takang menunjukkan pergerakkan yang sangat baik, hal ini disebabkan oleh kondisi cuaca, dan waktu istirahat siang, karena waktu istirahat tersebut dapat mengembalikan stamina para tukang yang bekerja. Pada pengamatan tukang hampar didapatkan siklus dengan variasi pengambilan antara pagi, siang, dan sore.

Tabel 4. Pengamatan Tukang Pembesian

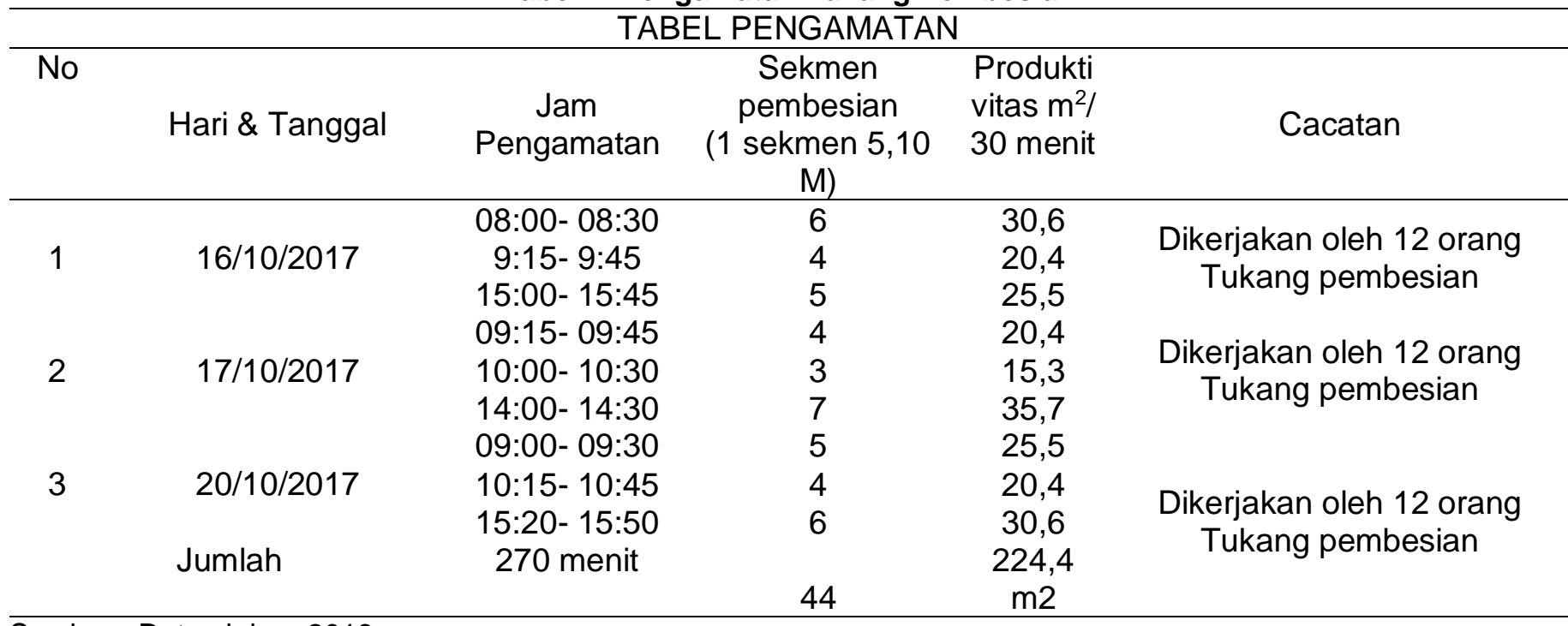

Sumber : Data olahan 2018

Hasil pengamatan pada tabel diatas dapat dilihat siklus waktu pelaksanaan pembesian beserta produktivitas yang dihasilkan selama 30 menit, pada pengamatan tukang pembesian, apabilah dilihat dari tabel diatas maka dapat dilihat pada pengamatan pertama selama 30 menit didapat produktivitas tukang $30,6 \mathrm{M}^{2}$, sedangkan untuk pengamatan selama tiga hari dengan waktu 270 menit dengan produktivitas 224,4 $\mathrm{M}^{2}$,dari hasil pengamtan maka dapat lihat semakin sore maka produktivitas takang menunjukkan pergerakkan 
yang sangat baik, dapat dilihat pada tabel diatas nilai tertinggi hasil pekerjaan di peroleh pada sore hari dengan jumlah $35,7 \mathrm{M}^{2} / 30$ menit.

Tabel 5. Hasil Pengamatan Pada Tukang

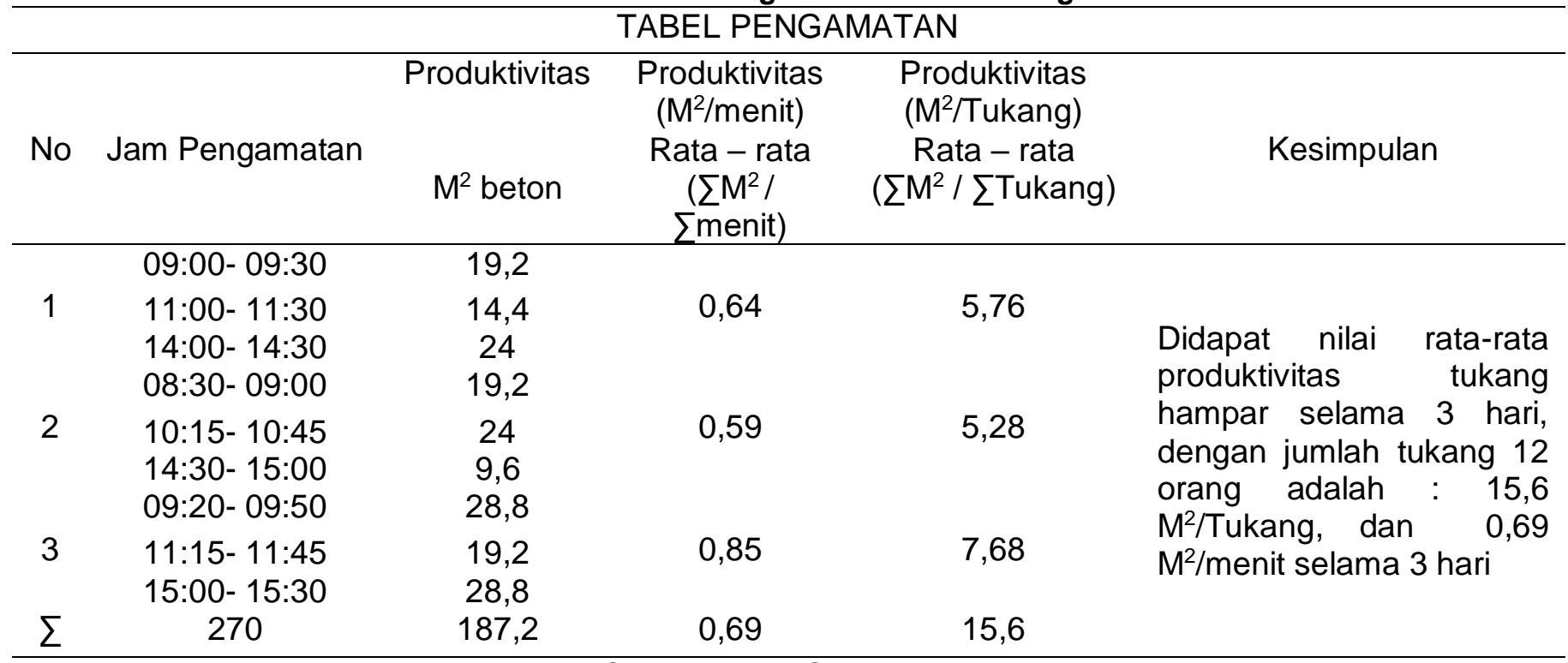

Sumber : Data Olahan 2018

Dapat dilihat pada kolom jam pengamatan menunjukkan bahwa penelitian dilakukan pada pagi hari, siang, dan sore hari. pada satu siklus pengamatan (30 menit) untuk tiga hari. Kolom produktivitas diperoleh dari jumlah produksi yang dihasilkan tukang selama siklus pengamatan. Setelah data terkumpul maka dapat dilakukan perhitungan sebagai berikut.

a. Produktivitas rata- rata pada hari pertama

$$
=19,2+14,4+24
$$

90 menit

$=0,64 \mathrm{M}^{2} /$ menit

b. Produktivitas rata-rata yang dilakukan selama 3 hari pada satu siklus pengamatan

$$
\begin{aligned}
=\quad \sum \frac{\mathrm{M}^{2} \text { Beton }}{\text { menit }} & 187,2 \mathrm{M}^{2} \\
& 270 \text { menit } \\
= & 0,69 \mathrm{M}^{2} / \text { menit }
\end{aligned}
$$

c. Produktivit as rata-rata setiap tukang selama tiga hari

$$
\begin{aligned}
& =\frac{\sum \mathrm{M}^{2} \text { Beton }}{\sum \text { Tukang }}=\frac{187,2 \mathrm{M}^{2}}{12} \\
& =15,6 \mathrm{M}^{2} / \text { Tukang }
\end{aligned}
$$

Dapat dilihat pada hari pertama tukang memiliki produktivitas rata-rata $0,69 \mathrm{~m} 2 /$ menit, jadi tukang ini termasuk dalam klasifikasi beban kerja yang ringan, sehingga dapat disimpulkan bahwa tukang belum mengalami kelelahan dan masih bisa mengoptimalkan waktu kerja yang diberikan.

\section{SIMPULAN}

1. Dari 24 orang tukang yang diteliti, maka didapat profil tukang berdasarkan usia yang dominan adalah usia 26 tahun sampai dengan 30 tahun dengan jumlah 55 $\%$, dan diatas 35 tahun berjumlah $40 \%$.

2. Dari 24 orang tukang yang diteliti, dapat diketahui Pengalaman kerja tukang pada pekerjaan ini didominasi oleh pengalaman antara 2 sampai dengan 4 tahun dengan jumlah $85 \%$.
3. Produktivitas tukang rata-rata selama tiga hari yakni $0,64 \mathrm{M}^{2} /$ menit, dan 15,6 $\mathrm{M}^{2} /$ Tukang.

\section{DAFTAR PUSTAKA}

Afrialdi, Idil (2017). Tugas Akhir (S1). Universitas Batanghari. Jambi.

CV. Pengabuan Berdikari, (2017) "Subkont, Tenaga Kerja Proyek Jln.Sei.Saren-Teluk NilauSenyerang-Batas Riau" Jambi

PT. Sarang Teknik Canggi (2017) " Data Produksi Beton Bulan Oktober" Asbuilt Drawing Surveyor Jambi

Resapakti,Bayu.(2014).Tugas Akhir (S1). Universitas Batanghari. Jambi.

Undang- Undang Republik Indonesia (2003) "NO. 13 Tentang Tenaga Kerja dan
Waktu Kerja" 
Wolfram I Ervianto (2002) "Manajemen Proyek Konstruksi" ANDI, Yogyakarta. Wignjosoebroto, Sritomo (2003)"Studi Gerak dan waktu teknik Analisis Untuk Peningkatan Produktivitas Kerja" PT . Guna Widya : Jakarta 